\title{
OPERA IN CINEMA: ASPECTS OF VIDEO EXPRESSIVE MEANS IN MODERN OPERA
}

Over a century ago the world was presented with cinema; a new dimension, art and craft of video recording, editing and reproduction. The initial purpose of this new technology rested on the idea of the ability to catch, fixate, and reproduce, visually repeat events and experiences. People of art immediately realized that proper application of such a promising tool may result in nothing less than a new genre. Cinema offered a new combination of expressive means, a synthesized language that could visualize, interpret, create and recreate via means of mechanics, plastics and choreography, gestures and illusions. Although over a century ago skeptics argued that cinema could not compete with the complex and sophisticated world of theater, art lovers have not only resided in movie theaters, but the theater itself ended up migrating to the cinema grounds. Recording, broadcasting, live streaming, film adaptation and other uses of video techniques became a regular practice in theater, especially musicals, and, finally, reached opera.

The study is devoted to the aspects of various application of video in opera. It is important to, first of all, enlist and describe the video phenomena one may encounter in modern opera context. It is then possible to analyze the way video techniques affect expressive principles and aesthetic basis of opera. Finally, it is necessary to sum up the positive effects that such video and media techniques bring to the marketing approaches in opera. In conclusion, the current state of opera as changing art and adaptive creative industry can be summarized and reviewed.

\section{Application of video techniques on an opera stage}

There are multiple ways modern opera exploits or may exploit video technology. The most fruitful and frequently used ones are recording and reproduction, publishing, video projection, film adaptation, broadcasting and live streaming.

The only reason it is still possible to watch and listen to such opera legends as Maria Callas, Luciano Pavarotti, Joan Sutherland and others is audio and video recording. The majority of the legendary performances and stagings are recorded, 
multiplied, published and represented on CD, VHS, DVD, Blu-ray discs and other digital carriers. The opera and theater heritage is therefore preserved and may be reproduced in time and space, in earlier unreachable areas and decades.

What is more interesting about opera recordings is that they are usually reproduced in places and time periods that are not typical for this genre. A video file with an opera may be played at home, in a classroom, in a park, in an airplane; it may be started early in the morning, during a lunch break or late at night. These peculiar settings inevitably change the traditional social code and protocol of an opera event in the 20th century; they don't correspond with the finesse and exclusivity of an evening in an opera house. Quite the opposite, they symbolize adaptiveness of such an unique and sophisticated tradition to the call of the creative industries ${ }^{1}$ and modern community of art lovers and art fans.

There is the pressure of creative, or cultural, industries with their tendencies to turn art into entertainment ${ }^{2}$, and manage the entertainment in the best traditions of the new economy and art marketing. ${ }^{3}$ Opera is supposed to provide a very unique live experience in time and space, but the times demand every art to become flexible and correspond to the needs of the audience; record, multiply and reproduce, if needed, deliver the product to one's doorstep if possible. The main idea of creative industries is to adapt the world of art to the principles of marketing, therefore, to intensify the production, expand the audience and maximize the profit. Intensifying the production here does not mean to make as many stage production as possible, as often as possible, but rather to multiply and reproduce the existing productions via means of recording, broadcasting and streaming.

Recording and publishing opera also responds to the trend of ,nobrow' community. According to John Seabrook, modern audiences are not segregated into ,taste clusters anymore; the diversity of entertainment and the blurry borders of social classes nowadays allow everyone to pick their own set of personal preferences without any limitations, restriction, rules or logic. ${ }^{4}$ It means that one may easily enjoy a popular TV show in the morning while admiring a classical ballet in the evening. It means that anyone anywhere may wish to spend some time on opera disregarding the anchors of personal taste, influence of reference groups and background. The natural curiosity of modern art fans and the openness and

1 The concept of creative or cultural industries in this article is referred to the studies of David Hesmondhalgh, eg. The Cultural Industries. SAGE Publications Ltd; Third edition, 2012.

2 The critical aspects of the culture industries are exposed in the notorious study of Theodor Adorno and Max Horkheimer, The culture Industry: Enlightenment as Mass Deception, 1944. [Online]. [Accessed on 6.11.2015]. URL: https://www.marxists.org/reference/archive/ adorno/1944/culture-industry.htm.

DOLGIN, Alexander. Manifesto of the New Economy. Institutions and Business Models of the Digital Society. [Online]. [Accessed on 29.09.2015]. URL: http://adolgin.com/downlo$\mathrm{ad} /$ ?type $=$ pdfen.

4 SEABROOK, John. Nobrow. The Culture of Marketing, the Marketing of Culture. Vintage, 2001. 
adaptiveness of the art itself predispose a shift of audience groups and clusters which may result in growing numbers of opera audience in general.

Recording and publishing also solve many problems of physical and psychological barriers that stop potential audience from attending opera theaters. For example, a DVD played in the comfort of home could be a better choice for those who do not have enough time, money or wish to plan a trip to an actual opera house. A copy of an opera production can be manipulated by the owner: from setting the sound and subtitles, to choosing a scene to play, as well as pausing, skipping, rewinding, stopping and restarting. As a result, the new nobrow audiences may find the world of opera rather amusing than strict for it offers to control the situation, and not being controlled by its strict protocols and traditions. Such a ,frivolous' approach to opera cannot go unnoticed; it demolishes superstitions that were there for decades and welcomes to an experiment.

In order to reach larger audience, opera goes even further and offers art lovers broadcasting and live streaming. Using modern media technologies, the Internet and television, as well as projectors and screens in cinemas and opera houses, opera postulates its up-to-date status and readiness to be flexible and change. Premiers in notorious opera houses are live streamed online (web pages, streaming channels, online TV channels) $)^{5}$, and broadcast on TV (TV channels like Mezzo or Arte, local TV channels) and in cinemas and opera houses ${ }^{6}$, sometimes even outside the opera house and on the streets. ${ }^{7}$ Streaming and broadcasting makes opera more open and accessible by bringing it to the urban space and the Internet, by delivering the end product or its samples straight to the potential audience.

Expansion and migration of opera outside of its grounds suggests the new understanding of the whole social convention of going to theater, specifically to an opera. It does not necessarily means an expensive ticket, exclusive experience, sophisticated community and strict dress and behavior codes anymore. Watching an opera may be as informal as it goes as well as less ceremonious and strict than we are used to imagine.

In its adaptiveness and readiness to be up-to-date opera does not neglect cooperation with video and media arts on stage: ,opera productions must negotiate a path between ,traditional' stagings and those ,updated in pursuit of relevance. ${ }^{6} 8$ Apart from adapting to be recorded, reproduced and streamed, opera takes advantage of video techniques in the very production. Integrating video projection and streaming into a stage production is a common practice in modern theater in general. Video in opera may be used to arrange a setting, demonstrate simultaneous

5 Eg. The Opera Platform web page that is supported by European Union. URL: http://www. theoperaplatform.eu/ [accessed 1.11.2015].

6 See recent productions of Metropolitan Opera House that are broadcast in HD Live. URL: http://www.metopera.org/Season/In-Cinemas/ [accessed 7.11.2015].

7 See Vienna State Opera that broadcasts its live stage productions on one of its walls.

8 GREENWALD, Helen M. The Oxford Handbook of Opera. Oxford University Press, 2014, p. $23-1177$ p. 
actions, zoom in a characters to demonstrate details of facial expressions ${ }^{9}$, collide characters ${ }^{10}$ or transmit classic plots to the new era of television and media ${ }^{11}$. In other words, video became one of largely used expressive means in opera theater.

One more fruitful way of synthesizing opera and cinema languages is film adaptation. It represents transition of genres through interpretation of an original work via means of visual and audio tools and techniques. Film adaptation of literature, history, biographies, mythology transmits temporal material into spatialtemporal dimension ${ }^{12}$; interpretation of spoken and written language with choreographic, plastic and musical language synthesizes a new genre ${ }^{13}$. The result of film adaptation of an opera is synthesis of two temporal-spatial genres submitted to rules and principles of the screen and projection.

The genre of opera employs adaptation of the work of spoken or written language (libretto). It elaborates the plot with its limited set of tools and interpret it within the dimension of the stage. This includes application of multiple musical, spatial-temporal, plastic, choreographic and acoustic languages. The initial abstraction of a story is being materialized in multiple dimensions, the images are described in details and fixated in time and space. The result is rather objective and specified to the limit thanks to the multiplicity of expressive means. Alike literature, with its temporal stylistic language, opera employs acoustics and visuals to formalize and objectify an abstract plot.

The story of Eugene Onegin was initially a novel in verse written by Alexander Pushkin. Despite of many adjectives used by the poet, readers would need a big deal of concentration, fantasy and knowledge of specific history and culture to build up the scenery and outline the characters in their imagination. The world celebrated opera adaptation by Petr Tchaikovsky presents a clear idea of each character's humour; the palette of musical expressive means allowed the composer to design distinguishable characters of a snob, a dreamer, a romantic. The outline of the characters are fixated not only with their musical themes, but also on the stage with costumes, gestures, postures, body language, light management and special effects. The result of Eugene Onegin production gives very clear ideas of director's understanding of the characters; what they look like, how they carry themselves and how others correspond with them.

Film adaptation of opera maximizes and specifies the plot at most. Apart from the absolute (hyper) realism in front of the camera, cinema plays with editing techniques and special effects that add non-theatrical, real life dramatic effects. Film adaptation is also capable of presenting a realistic setting, whether it is

\footnotetext{
9 BORODIN. Prince Igor. [DVD]. Metropolitan Opera House, 2014.

10 GLINKA. Ruslan and Lyudmila. Bolshoi Theater, 2011.

11 HANDEL. Orlando. [DVD]. Zurich Opera, 2007.

12 According to the structural analysis of arts and genres of Soviet aesthetic Moses Kagan. KAGAN, M. Lektsii po marksisto-leninskoj estetike. Leningrad: Izd-vo Leningr. Un-ta, 1971.

13 The theory of expression means and stylistic languages taken from the study of Yuri Lotman. LOTMAN, Y. Struktura khudozhestvennogo teksta. Moskva: Izdatelstvo "Iskusstvo", 1970.
} 
recorded in a pavilion or open air. ${ }^{14}$ Editing manages the story flow and helps to shorten the plot. ${ }^{15}$

Another ability of cinema to counterfeit and adjust realism is to replace the visual image of a singer, performer of the musical text, with a standardized beauty, a professional movie actor who rather resembles the character. ${ }^{16}$ Film adaptation synthesizes two performers in one in favor to get a clean picture with strong audio.

Productions of Eugene Onegin on a stage are far from the abstraction of the initial text; the plot gains body and shape and loses dimensions of free interpretation. In the film adaptation of the opera the plot, the scenery and each and every of the characters is fixated and specified to details: close-ups demonstrate facial features, micro-expressions of characters, details of their clothing, shades of the scenery, locations where the action is set. Musical text pumps the volume of the colorful picture and the video editing soothes the story flow. Audience is presented with a very specific, steady and elaborated end product which does not need to be interpreted. The excess of stylistic languages and mixture of expressive means unique to literature, opera or cinema recycle the same abstraction of the initial source and frees the audience from the labor of imagining and interpreting.

Exploitation of video on stage invoke internal and external changes of modern opera; these are traditionalist challenges in the aesthetic theory of it and new opportunities for its marketing and promotion.

\section{New aspects of opera promotion}

Massive and expansive usage of video advantages in opera manage to spread the productions of local opera houses all over the world; bring the very idea and art of opera to one's house, club, classroom. While video and audio recordings allow local productions to reach other countries and cultures, live streaming and broadcasting bring opera to the Internet community and TV coach fans. The technological advances of opera broadcast dramatically lower the affective filter of potential audience. Art lovers who used to be skeptic about the social protocol, fancy dressing-up and following the etiquette procedures may now enjoy opera in their PJ's on a couch, may pause, rewind and replay it as much as they like, as well as watch it in any time of a day and any day of a week despite of the local opera house programme. In fact, art lovers and fans do not even need to be

14 For example, the soviet adaptation of Queen of Spades includes several scenes in the Summer Garden, Saint-Petersburg. See TCHAIKOVSKY. Queen of Spades. Film: directed by Roman Tikhomirov. Lenfilm studio, Leningrad (Soviet Union), 1960.

15 See Vera stroyeva's film adaptations of the two epic operas by Modest Moussorgsky, ,Boris Godunov“ (1956, Mosfilm) and ,Khovanschina' (1960, Mosfilm).

16 See the example of the full cast of performers, including Galina Vishnevskaya as Tatyana, is being replaced on the screen by professional film actors: TCHAIKOVSKY. Eugene Onegin. Film: Lenfilm, Leningrad 1958. 
dependent on the local opera house repertoire. The world most notorious productions of renowned opera houses are within the reach of a cinema or theater goer nowadays. Strong brands like MET and ROH sustain their international fan community by offering live streaming and broadcasting, while less known among the non-opera community brands, such as Glyndebourne festival, gain publicity by DVD publishing and online streaming.

Another advantage of video technologies in conquering the audience is its reach to realistic image and movie-like attitude. First of all, thanks to video special effects and advantages of video editing, the action becomes more engaging, dynamic and clear. Secondly, the High Definition of the image, being extremely demanding, presents a lot of movie-like close-ups. Combination of the two makes new audiences be more willing to engage with the plot and follow the visual exposure of facial expressions, gestures, scenery and costume details that are so hard to spy on from an opera house chair. As a reviewer, Roxana Robinson puts it: ,But as to the performance itself, HD is brilliant. If exquisite music and powerful emotion are the great engines of opera, HD delivers. It's as though a scrim has been lifted: everything is sharper and more vivid. Even the music seems truerbut the great change is visual. The camera provides the one thing that the Met can't: intimacy. The vast stage and enormous house keep us at a distance, and a view through opera glasses is cramped and tiny. The camera's quiet close-ups offer an entirely new rendering, where love and grief and rage become personal: the swelling throat, the trembling mouth, the welling eye. We watch Brünnhilde's grieving face as she yields to her father's sorrowful decree, Rigoletto's, as he understands his bitter fate. ${ }^{617}$

The advantages of video technology in opera are, of course, monetary, too. Reaching larger numbers of potential audience, lowering its affective filter and, therefore, seducing and conquering new fans solidifies the community of opera goers and followers. It results in increased numbers of customers willing to purchase tickets, audio recordings, DVDs, books, souvenirs, and subscriptions. One night performance may raise the funds of an opera thanks to video recording and publishing (DVD, Blu-Ray, digital copy, etc.), prepaid online streaming, international broadcasting in cinemas and opera houses, subscription, and the very tickets and brochures sold for the performance.

\section{Aesthetics of the HD. Notes on the changing nature of opera.}

Application of video technology in production and distribution of opera is a tricky business. On the one hand, it does result in a certain growth of audience and creating the community; it also serves the purpose of adapting and improving

17 ROBINSON, Roxana. Can Opera Play at the Movies? The New Yorker. March 1, 2013. [Online]. [Accessed on 7. 11. 2015]. URL: http://www.newyorker.com/culture/culture-desk/ can-opera-play-at-the-movies. 
the genre according to the changing demands of creative industries. On the other hand, the aesthetics of hyperrealism (HD, special effects and video editing) ${ }^{18}$ combined with intensification of production, publishing and reproduction of opera evoke the criticism of simulation ${ }^{19}$, falsification, commodification and industrialization ${ }^{20}$ of art.

Hollywood used to be one of the pioneers that served to the concept of hyperrealism, that is to adapt and simplify creative content to the extent where art work becomes so clear, direct, restricted and reserved, that it is no more open to a free interpretation; it became a ready product of pure entertainment. ${ }^{21}$ If opera wants to become less abstract, more realistic, and easier to be consumed, video editing, $\mathrm{HD}$, universal beauty standards and special effects come in handy. The complex of the tools provides a sleek and clean picture that resembles a blockbuster film rather than a theater production. If it is good or bad one cannot say; despite of the theorists trying to revoke such a twist in the evolution of a traditional respected art, audience finds the new way opera is dealing with the market challenges inspiring ${ }^{22}$. One thing is certain: opera has been changing for centuries and we are now observing a new coil of a spring.

Opera began as a social event, higher and lower classes convention, a meeting, gossip and exposure point for various society layers in the 16th century. ${ }^{23}$ However, a couple decades ago a visit to an opera would be full of strict etiquette rules and protocols, an extraordinary event, a social gathering where one may expose oneself and peer at others while enjoying sophisticated collisions, musical texts and singers' skills, something quite unique and outstanding for an everyday listening. Today, one may show up in an opera house with, Valkyrie helmets, with small curved horns ${ }^{64}$ on, or appear in a cinema for an opera broadcast in ,sweaters and parkas and boots, honoring the god of weather, not opera ${ }^{625}$. It seems that opera does not represent the classy social interaction, an outstanding experience opposed to mundane everyday activities anymore.

18 BAUDRILLARD, Jean. Simulacra and Simulation (The Body, In Theory: Histories of Cultural Materialism). 17th Printing Edition, University of Michigan Press, 1995.

BAUDRILLARD, Jean. For a Critique of the Political Economy of the Sign. Telos Press Publishing, 1981.

ADORNO, Theodor - HORKHEIMER, Max. The Culture Industry: Enlightenment as Mass Deception, 1944. [Online]. [Accessed on 6. 11. 2015]. URL: https://www.marxists.org/reference/archive/adorno/1944/culture-industry.htm. Ibid.

22 WEISGALL, Deborah. Loving the Opera in HD. The American Prospect. [Online]. [Accessed on 3.11.2015]. URL: http://prospect.org/article/loving-opera-hd.

23 SNOWMAN, Daniel. The Gilded Stage: A Social History of Opera. Atlantic Books, 2010.

24 ROBINSON, Roxana. Can Opera Play at the Movies? The New Yorker. March 1, 2013. [Online]. [Accessed on 7. 11. 2015]. URL: http://www.newyorker.com/culture/culture-desk/ can-opera-play-at-the-movies.

Ibid. 
Another aspect of the authenticity in modern opera is the questionable transmission of a performance into a digital recording, fixating it in its singularity and reproducing it outside of a theater. Such a practice does not only raises questions about the uniqueness of a singular live experience. It puts doubt on the very essence of an opera as a social event. With online streaming opera made it to the Internet. HD recording and broadcasting brought it to homes. The conflict of a gilded opera box with a web browser tab, a smoking with a sweater, a fulllength here-and-now experience with a cropped short video played from cheap speakers sounds dramatic. However, this is the way modern opera is ready to compromise in order to survive under the pressure of creative industries and art markets. The chosen strategy opens new horizons for both opera productions and potential audiences, for if a grand expensive genre like this could have made a step down from its stage, and reach to its fans, then it will be capable of answering to upcoming challenges of the market and adapt without changing its very core idea, techniques and principles.

Since opera had decided to pick the advantages of video technologies in order to renovate and adapt to challenges of creative industries, it has gone through a certain formal change. It expanded its territory and grew its community, regulated its traditions and simplified its social protocols. Despite of many gains, it was not a radical swap. Modern opera keeps itself within the borders of the genre, while experimenting with media, technologies, languages and means of interpretation. It dares and stays flexible by responding to the external calls and demands and, thanks to the video technologies, it manages to stay up-to-date without conceptual dramatic changes in the core.

Elena Khokhlova (403149@mail.muni.cz), Ústav hudební vědy, Filozofická fakulta, Masarykova univerzita, Brno, CZ.

\begin{abstract}
The study represents an overview of various video techniques, such as film adaptation, recording and broadcasting, live streaming, video projection used in modern opera. The author argues that by large application of these techniques, opera protects its position of modern and adaptive art and responds to the challenge of creative industries. Although practices of recording, reproduction, and massification in authentic and pure experience genres could be considered questionable by some art scholars and theorists, opera implements them to enrich its set of expressive means and correlate with the modern market challenges.
\end{abstract}

\title{
Key words
}

video, opera, recording, promotion, audience, celebrity, HD, broadcast, live stream, aesthetics, reproduction, authenticity, social code 


\section{Bibliography}

ADORNO, Theodor - HORKHEIMER, Max. The culture Industry: Enlightenment as Mass Deception. 1944. [Online]. [Accessed on 6. 11. 2015] URL: https://www.marxists.org/reference/ archive/adorno/1944/culture-industry.htm.

ALMQUIST, Sharon G. Opera Mediagraphy: Video Recordings and Motion Pictures. Music Reference Collection (Book 40). Greenwood, 1993.

BAUDRILLARD, Jean. For a Critique of the Political Economy of the Sign. Telos Press Publishing, 1981.

BAUDRILlARD, Jean. Simulacra and Simulation (The Body, In Theory: Histories of Cultural Materialism). 17th Printing Edition, University of Michigan Press, 1995.

DOLGIN, Alexander. Economics of Symbolic Exchange. Springer, 2008.

DOLGIN, Alexander. Manifesto of the New Economy. Institutions and Business Models of the Digital Society. [Online]. [Accessed on 29. 09. 2015]. URL: http://adolgin.com/download/?type=pdfen. GREENWALD, Helen M. The Oxford Handbook of Opera. Oxford University Press, 2014.

HESMONDHALGH, David. The Cultural Industries. SAGE Publications Ltd, Third Edition edition, 2012.

KAGAN, Moisej. Lektsii po marksisto-leninskoj estetike. Leningrad: Izd-vo Leningr. Un-ta, 1971.

LISTER, Martin. New Media: A Critical Introduction. Routledge, 2009.

LOTMAN, Yurij. Struktura khudozhestvennogo teksta. Moskva: Izdatelstvo "Iskusstvo", 1970.

ROBINSON, Roxana. Can Opera Play at the Movies? [Online]. [Accessed on 7. 11. 2015]. The New Yorker, 1. 3. 2013. URL: http://www.newyorker.com/culture/culture-desk/can-opera-playat-the-movies.

SEABROOK, John. Nobrow: The Culture of Marketing, the Marketing of Culture. Vintage, 2001. SNOWMAN, Daniel. The Gilded Stage: A Social History of Opera. Atlantic Books, 2010.

WEISGALL, Deborah. Loving the Opera in HD. The American Prospect. [Online]. [Accessed on 3. 11. 2015]. URL: http://prospect.org/article/loving-opera-hd. 
